https://helda.helsinki.fi

Neutralization of solvated protons and formation of noble-gas hydride molecules : matrix-isolation indications of tunneling mechanisms?

Khriachtchev, Leonid

American Institute of Physics

2005-08-08

J. Chem. Phys. 123, 064507 (2005) (6 pages)

http://link.aip.org/link/?jcp/123/064507

Downloaded from Helda, University of Helsinki institutional repository.

This is an electronic reprint of the original article.

This reprint may differ from the original in pagination and typographic detail.

Please cite the original version. 


\title{
Neutralization of solvated protons and formation of noble-gas hydride molecules: Matrix-isolation indications of tunneling mechanisms?
}

\author{
Leonid Khriachtchev, ${ }^{\text {a) }}$ Antti Lignell, and Markku Räsänen \\ Laboratory of Physical Chemistry, P.O. Box 55, University of Helsinki, Helsinki FIN-00014, Finland
}

(Received 23 February 2005; accepted 23 May 2005; published online 16 August 2005)

\begin{abstract}
The $(\mathrm{NgHNg})^{+}$cations $(\mathrm{Ng}=\mathrm{Ar}$ and $\mathrm{Kr}$ ) produced via the photolysis of $\mathrm{HF} / \mathrm{Ar}, \mathrm{HF} / \mathrm{Kr}$, and $\mathrm{HBr} / \mathrm{Kr}$ solid mixtures are studied, with emphasis on their decay mechanisms. The present experiments provide a large variety of parameters connected to this decay phenomenon, which allows us to reconsider various models for the decay of the $(\mathrm{NgHNg})^{+}$cations in noble-gas matrices. As a result, we propose that this phenomenon could be explained by the neutralization of the solvated protons by electrons. The mechanism of this neutralization reaction probably involves tunneling of an electron from an electronegative fragment or another trap to the $(\mathrm{NgHNg})^{+}$cation. The proposed electron-tunneling mechanism should be considered as a possible alternative to the literature models based on tunneling-assisted or radiation-induced diffusion of protons in noble-gas solids. As a novel experimental observation of this work, the efficient formation of HArF molecules occurs at $8 \mathrm{~K}$ in a photolyzed $\mathrm{HF} / \mathrm{Ar}$ matrix. It is probable that the low-temperature formation of $\mathrm{HArF}$ involves local tunneling of the $\mathrm{H}$ atom to the Ar-F center, which in turn supports the locality of HF photolysis in solid Ar. In this model, the decay of $(\mathrm{ArHAr})^{+}$ions and the formation of HArF molecules observed at low temperatures are generally unconnected processes; however, the decaying (ArHAr) ${ }^{+}$ions may contribute to some extent to the formation of $\mathrm{HArF}$ molecules. (C) 2005 American Institute of Physics. [DOI: 10.1063/1.1953467]
\end{abstract}

\section{INTRODUCTION}

The matrix-isolation technique has been used for several decades to study the physics and chemistry of trapped species. ${ }^{1}$ One important direction of research concentrates on photodissociation and photoionization of molecules, and various ionic and neutral species can be identified in these photolysis experiments. ${ }^{2}$ In particular, the UV photolysis of hydrogen-containing molecules can lead to the formation of $(\mathrm{NgHNg})^{+}$ions $(\mathrm{Ng}=\mathrm{Ar}, \mathrm{Kr}$, and $\mathrm{Xe})$, which is probably the simplest case of a solvated proton. ${ }^{2-4}$ These cations can also be trapped in noble-gas matrices upon direct deposition of hydrogen through discharge, as it was done in the pioneering works on these species. ${ }^{5-7}$ An intriguing question concerns the experimentally observed decay of the cations at low temperatures, which is not fully understood to date. For example, it was suggested that room-temperature background radiation could accelerate the diffusion of protons and deuterons in the matrix and explain the faster decay of protons. ${ }^{8}$ More recently, it has been proposed that protons could diffuse via a tunneling mechanism. ${ }^{9}$ In this model, proton diffusion is several orders of magnitude faster than that of deuterons, and the jump rate strongly increases from $\mathrm{Xe}$ to $\mathrm{Kr}$ and Ar, which is in qualitative agreement with the available experimental data on these species.

As a related subject, experiments with the photolysis of hydrogen-containing species have constructed the basis for the preparation and identification of noble-gas hydride molecules with general formula $\mathrm{HNgY}$ ( $\mathrm{Y}$ denotes an elec-

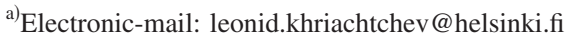

tronegative fragment, such as $\mathrm{F}, \mathrm{OH}, \mathrm{CCH}$, etc.). ${ }^{10}$ As an example, the first neutral ground-state chemical compound containing argon, HArF, was prepared using the vacuum-UV photolysis of $\mathrm{HF}$ in solid $\mathrm{Ar}$ at $7 \mathrm{~K}$ and by annealing at $\sim 20 \mathrm{~K}^{11}$ The formation of $\mathrm{HNgY}$ molecules via the $\mathrm{H}$ $+\mathrm{Ng}+\mathrm{Y}$ reaction of the neutral fragments was directly demonstrated in the case of HXeI. ${ }^{12}$ It was not an evident fact because of the charge-transfer nature of these molecules showing the strong $(\mathrm{HNg})^{+} \mathrm{Y}^{-}$character and the presence of the $(\mathrm{NgHNg})^{+}$ions in most of those experiments. Indeed, one could connect the annealing-induced decay of $(\mathrm{NgHNg})^{+}$ ions and the formation of $\mathrm{HNgY}$ molecules, but this does not seem to be the general case. Moreover, two examples were later found when photolysis did not produce $(\mathrm{NgHNg})^{+}$ions in detectable amounts, but annealing efficiently generated the $\mathrm{HNgY}$ molecules $\left(\mathrm{HKrCN}\right.$ and $\left.\mathrm{HKrC}_{4} \mathrm{H}\right){ }^{13,14}$ The annealing-induced formation of $\mathrm{HNgY}$ molecules ( $\geqslant 25$ and $37 \mathrm{~K}$ in $\mathrm{Kr}$ and $\mathrm{Xe}$ matrices, respectively) was used to study the diffusion of hydrogen in solid $\mathrm{Kr}$ and Xe. ${ }^{15,16}$ The atomic hydrogen diffusion in solid Ar has not been studied in detail so far. Some indications exist that the hydrogen mobility in solid $\mathrm{Ar}$ is rather a local process than a global one,${ }^{17}$ meaning that the formation of HArF might be somewhat different from the formation of other $\mathrm{HNgY}$ molecules.

Another link between the $(\mathrm{NgHNg})^{+}$ions and the $\mathrm{HNgY}$ molecules is remarkable. It was shown that in some (if not in all) cases the photodissociation of small hydride molecules in noble-gas solids is a local process. This concept means that the dissociating hydrogen atom is localized at a short distance (comparable with the lattice parameter) from the parent cage. First, this locality allows direct light-induced 
formation of the $\mathrm{HNgY}$ molecules. Next light pulses can decompose the formed molecules but, in some cases ( $\mathrm{HXeNCO}, \mathrm{HKrCl}$, and $\mathrm{HArF}$ ), their formation is detected directly. ${ }^{11,18,19}$ Based on the data obtained for HXeI, this direct formation takes place also for other $\mathrm{HNgY}$ species but their steady-state concentration is minor because of the very fast photodecomposition. ${ }^{20}$ Second, the formation of the $(\mathrm{NgHNg})^{+}$ions can influence the final spatial distribution of $\mathrm{H}$ atoms. In this image, the electronegative fragment enhances the electron transfer from the surrounding host, and the dissociated hydrogen atom captures the created hole. The repeated neutralization and formation of $(\mathrm{NgHNg})^{+}$ions can move the hydrogen atom to a longer distance from the parent cage, as discussed elsewhere. ${ }^{20}$

In the present work, we analyze the experimental data on the decay of $(\mathrm{NgHNg})^{+}$ions and the formation of $\mathrm{HNgY}$ molecules in low-temperature matrices. We concentrate mainly on experiments in solid Ar, where HArF is formed, and present some comparison with experiments in $\mathrm{Kr}$ matrices. We discuss various mechanisms that can explain the experimental data. For the decay of the $(\mathrm{NgHNg})^{+}$ions, we propose a possibility of their neutralization via an electrontunneling mechanism. For the low-temperature formation of $\mathrm{HArF}$ molecules, the hydrogen atom tunneling is a probable mechanism.

\section{EXPERIMENT}

\section{A. Experimental details}

The $\mathrm{HF} / \mathrm{Ar}, \mathrm{HF} / \mathrm{Kr}$, and $\mathrm{HBr} / \mathrm{Kr}$ solid mixtures were studied in a closed-cycle helium cryostat (APD, DE 202A) at temperatures down to $8 \mathrm{~K}$. The $\mathrm{HF} / \mathrm{Ar}$ and $\mathrm{HF} / \mathrm{Kr}$ matrices ( $\sim 100 \mu \mathrm{m}$ thick) were deposited onto a cold CsI substrate by passing $\mathrm{Ar}$ and $\mathrm{Kr}$ gas (AGA) over a HF-pyridine polymer (Fluka) at room temperature. In order to prepare deuterated samples, the $\mathrm{HF} / \mathrm{Ng}$ mixture was passed through a line with deuterated sulfuric acid, and the deuteration degree was up to $90 \%$. ${ }^{11}$ The photolysis of $\mathrm{HF}$ was performed with a $\mathrm{Kr}$ continuum lamp (Opthos) emitting in the 127-160 nm spectral interval, the decomposition proportion being typically $20 \%$ after $30-60 \mathrm{~min}$ of irradiation, limited probably by photogenerated light absorbers. ${ }^{21}$ The $\mathrm{HBr} / \mathrm{Kr}$ gas mixture $(1 / 500)$ was prepared by mixing $\mathrm{HBr}$ and $\mathrm{Kr}$ in a bulb. The 193-nm radiation of an excimer laser (MSX-250, MPB, pulse energy density $\sim 10 \mathrm{~mJ} \mathrm{~cm}^{-2}$ ) was used to photolyze $\mathrm{HBr}$ molecules, and typically $\sim 90 \%$ of $\mathrm{HBr}$ was decomposed after $\sim 1000$ pulses. The IR absorption spectra in the 4000 to $400 \mathrm{~cm}^{-1}$ region were recorded with a Nicolet 60 SX FTIR spectrometer using a resolution of $1 \mathrm{~cm}^{-1}$. Most of the $\mathrm{HF} / \mathrm{Ng}$ matrices were quite monomeric with respect to $\mathrm{HF}$, and the estimated $\mathrm{HF} / \mathrm{Ng}$ ratio was $\sim 1 / 2000$. In particular, the doublet band of HF monomer at 3962.5 and $3953.8 \mathrm{~cm}^{-1}$ dominated in the IR absorption spectra in solid Ar, in agreement with the literature data. ${ }^{22}$

\section{B. Experimental results}

The IR absorption spectra in Fig. 1 demonstrate various steps of an experiment with HF in solid Ar. Some amount of $\mathrm{HArF}$ is seen already after the vacuum ultraviolet (VUV)

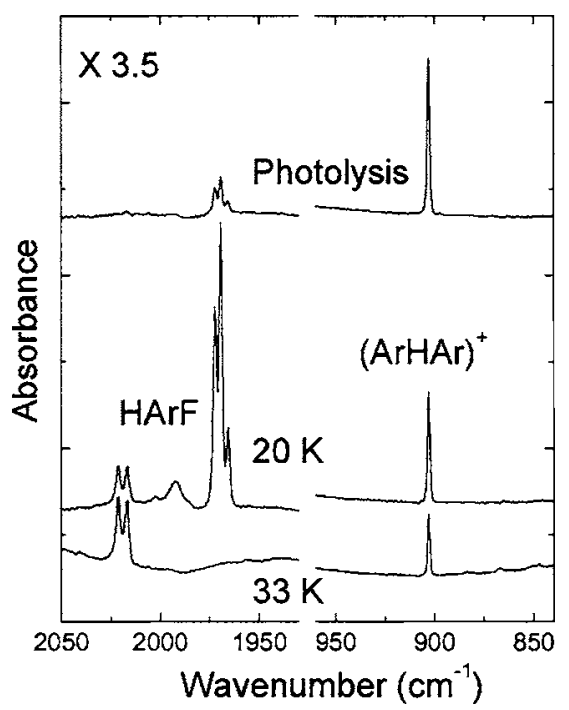

FIG. 1. (ArHAr) ${ }^{+}$and HArF in solid Ar. Shown are (from top to bottom) fragments of IR absorption spectrum after the VUV photolysis of the HF/ Ar matrix, the spectrum after annealing of the photolyzed matrix at $20 \mathrm{~K}$, and the spectrum after annealing of the same sample at $33 \mathrm{~K}$. The annealing time was $\sim 3 \mathrm{~min}$. The spectra were measured at $8 \mathrm{~K}$. The deposition temperature was $8 \mathrm{~K}$. The multiplying factor of 3.5 is applied to the higherfrequency part of the plot.

photolysis and, simultaneously, (ArHAr) ${ }^{+}$ions are formed, evidenced by the IR absorption band $\nu_{3}$ at $903 \mathrm{~cm}^{-1}$. Annealing at $20 \mathrm{~K}$ further increases the concentration of HArF with triplet absorption at $1965.7,1969.4$, and $1972.3 \mathrm{~cm}^{-1}$ and a broad feature around $1992 \mathrm{~cm}^{-1}$ and promotes the doublet absorption at 2016.3 and $2020.8 \mathrm{~cm}^{-1}$ that belongs to HArF as well. ${ }^{23,24}$ The triplet absorption and the broad feature decrease and disappear upon annealing above $28 \mathrm{~K}$. The doublet absorption has a larger thermal stability, and it was assigned to HArF in a thermally relaxed solid-state configuration (matrix site) and was called "stable" HArF in order to distinguish it from the "unstable" HArF absorbing at $\sim 1970 \mathrm{~cm}^{-1}$. $^{23}$ The stable and unstable configurations correspond to molecules in certain local matrix morphologies. The $1992-\mathrm{cm}^{-1}$ band probably originates from the hindered rotation of HArF in an Ar matrix, in analogy with some other HNgY molecules. ${ }^{25}$ Upon annealing at 20 and $33 \mathrm{~K}$ the $(\mathrm{ArHAr})^{+}$concentration decreases; however, even after the $33-\mathrm{K}$ annealing the cations are very visible in the spectra.

Figure 2 presents the (ArHAr) ${ }^{+}$concentration versus the annealing temperature for four experiments with similar annealing periods. No reliable correlation between the deposition temperature and the decomposition rate of $(\mathrm{ArHAr})^{+}$ was found. It seems that the decay depends in a complicated way on the HF/Ar concentration and the efficiency of photolysis. Unfortunately, these two parameters are difficult to reproduce precisely in such experiments. We can conclude here qualitatively that the $(\mathrm{ArHAr})^{+}$concentration is quite stable in these experiments, especially taking into account that one annealing-measurement cycle is typically $20 \mathrm{~min}$ long.

Figure 3 compares the stability of $(\mathrm{NgHNg})^{+}$and $(\mathrm{NgDNg})^{+}$cations in $\mathrm{Ar}$ and $\mathrm{Kr}$ matrices. The annealing above $20 \mathrm{~K}$ for $\sim 3 \mathrm{~min}$ accelerates the decay process con- 


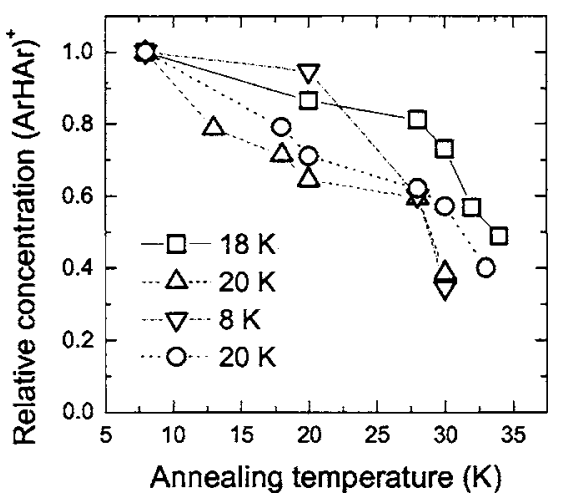

FIG. 2. Annealing-induced decay of (ArHAr) ${ }^{+}$cations. The annealing time was $\sim 3 \mathrm{~min}$. The annealing-measurement cycle was typically $20 \mathrm{~min}$ long. The (ArHAr) ${ }^{+}$concentrations are obtained by integrating the $903-\mathrm{cm}^{-1}$ band $\nu_{3}$ and are normalized by the initial value. The deposition temperatures are shown in the plot. The spectra were measured at $8 \mathrm{~K}$.

siderably as compared with the lowest working temperature (see below for experiments at $8 \mathrm{~K})$. The $(\mathrm{NgDNg})^{+}$cations are more stable than $(\mathrm{NgHNg})^{+}$, and the ratio of the corresponding rate constants $k(\mathrm{NgHNg})^{+} / k(\mathrm{NgDNg})^{+}$at the elevated temperatures is estimated to be 1.4 for $\operatorname{Ar}(30 \mathrm{~K})$ and 3.5 for $\mathrm{Kr}(24 \mathrm{~K})$. Furthermore, the stability of $(\mathrm{ArHAr})^{+}$ and $(\mathrm{KrHKr})^{+}$is also comparable at the elevated temperatures.

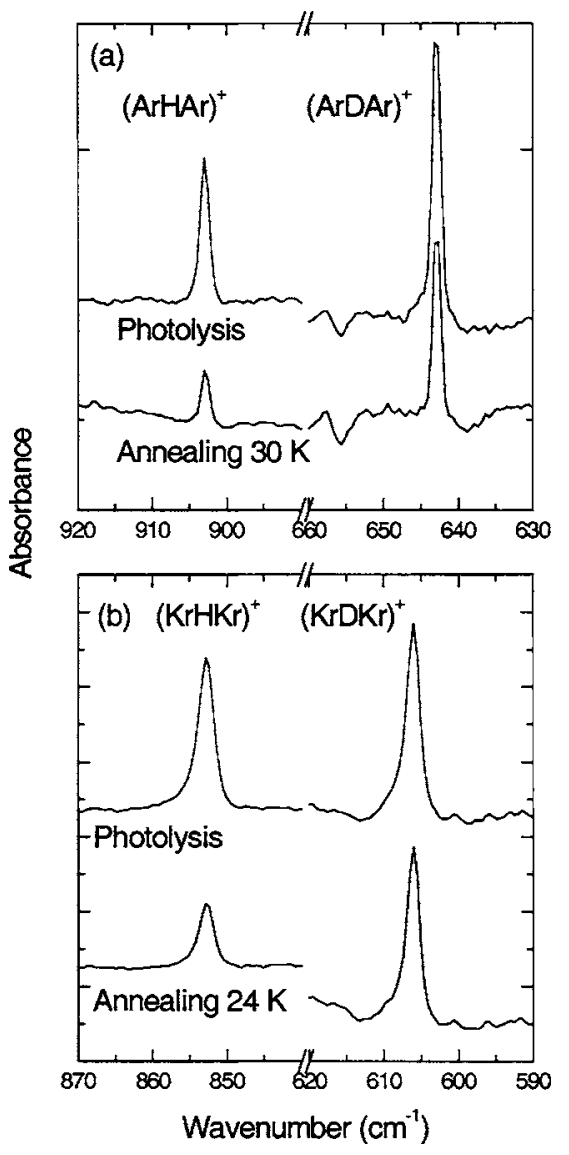

FIG. 3. Protons and deuterons solvated in (a) Ar and (b) Kr matrices. The IR absorption spectra correspond to the situations after the photolysis of $\mathrm{HF}(\mathrm{DF}) / \mathrm{Ar}$ and $\mathrm{HF}(\mathrm{DF}) / \mathrm{Kr}$ matrices and after annealing of the photolyzed matrices. The annealing time was $\sim 3 \mathrm{~min}$. The deposition temperatures were 8 and $20 \mathrm{~K}$ for $\mathrm{Ar}$ and $\mathrm{Kr}$ matrices, respectively. The spectra were measured at $8 \mathrm{~K}$.

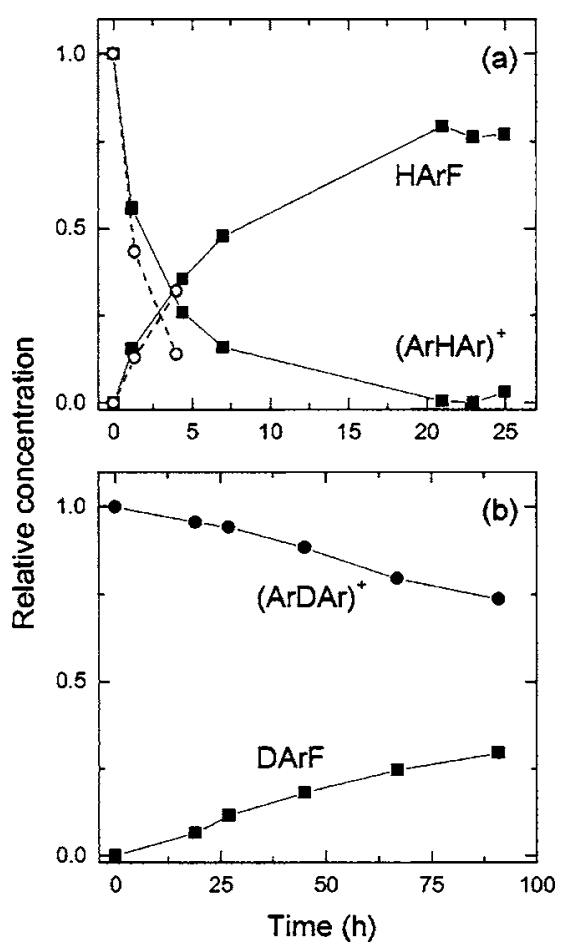

FIG. 4. (a) Decay of (ArHAr) ${ }^{+}$and formation of HArF (unstable configuration) in an Ar matrix at $8 \mathrm{~K}$ and (b) the same processes for the deuterated species. Open and solid symbols in panel (a) correspond to experiments in dark and under globar irradiations, respectively. The HArF and DArF concentrations are normalized by the values after additional annealing at $20 \mathrm{~K}$. Photolysis-produced HArF and DArF concentration is excluded from the kinetic data. The concentrations are obtained by integrating the corresponding IR absorption bands.

The $(\mathrm{ArHAr})^{+}$decay kinetics was measured at $8 \mathrm{~K}$, which is the lowest temperature of our apparatus (see Fig. 4). The $(\mathrm{ArHAr})^{+}$cations were found to decompose at $8 \mathrm{~K}$ on a time scale of hours. It should be mentioned that the start of measurement is delayed with respect to the formation of the cations mainly due to the photolysis time of 30-60 min. The decay upon globar irradiation [solid symbols in Fig. 4(a)] was compared with the decay in dark (open symbols). The present data show that the vibrational excitation of $(\mathrm{ArHAr})^{+}$ by globar radiation does not accelerate the decay process. The $(\mathrm{ArDAr})^{+}$decay at $8 \mathrm{~K}$ is slower by a factor of $\sim 200$ compared with the $(\mathrm{ArHAr})^{+}$decay, which is much larger than the corresponding difference estimated at elevated temperatures. Annealing at $20 \mathrm{~K}$ accelerates the $(\mathrm{ArDAr})^{+}$decay by a factor of $10^{3}$ as compared with $8 \mathrm{~K}$, which is a significantly larger enhancement than that for $(\mathrm{ArHAr})^{+}$, explaining the closer decay rates at the elevated temperatures.

A remarkable observation of this work concerns the lowtemperature formation of $\mathrm{HArF}$, and this similarly takes place under globar irradiation and in dark as seen in Fig. 4(a). It should be stressed that the delayed formation of the $\mathrm{HNgY}$ molecules has been usually promoted by annealing activating diffusion of hydrogen atoms in the matrix, with an important exclusion of IR-decomposed HXeI. ${ }^{10,12}$ In the present work, it is found that HArF (preferably the unstable configuration) can be slowly but efficiently produced in a photolyzed $\mathrm{HF} / \mathrm{Ar}$ matrix at $8 \mathrm{~K}$. The formation of DArF at $8 \mathrm{~K}$ is much slower, by a factor of $\sim 50$, than the formation of $\mathrm{HArF}$. 


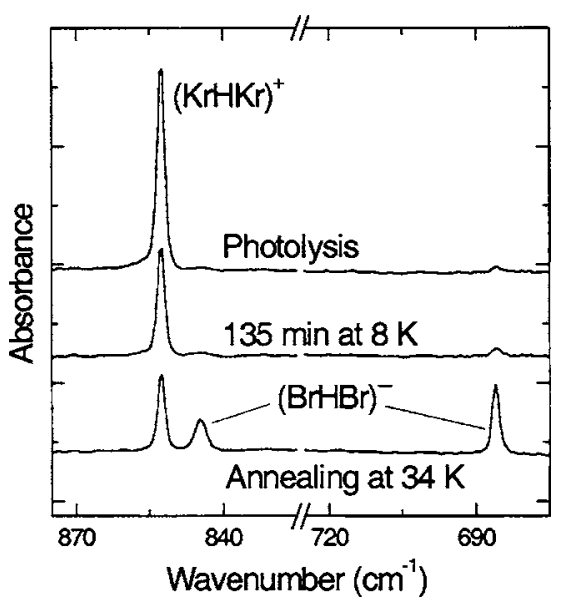

FIG. 5. ( $\mathrm{KrHKr})^{+}$and $(\mathrm{BrHBr})^{-}$in solid Kr. Shown are (from top to bottom) the fragment of an IR absorption spectrum after the 193-nm photolysis of the $\mathrm{HBr} / \mathrm{Kr}(1 / 500)$ matrix, the spectrum after $135 \mathrm{~min}$ at $8 \mathrm{~K}$, and the spectrum after annealing of the same sample at $34 \mathrm{~K}$ for $\sim 3 \mathrm{~min}$. The band at $844.5 \mathrm{~cm}^{-1}$ belongs to $(\mathrm{BrHBr})^{-}$. The matrix was deposited at $27 \mathrm{~K}$. The spectra were measured at $8 \mathrm{~K}$.

The formation of $\mathrm{HArF}$ at $8 \mathrm{~K}$ follows different kinetics from the decay of the (ArHAr) ${ }^{+}$cations. We fitted the data points using a stretched exponent $\exp \left(-k t^{\alpha}\right)$ and obtained $k$ $=(0.16 \pm 0.02) \mathrm{h}^{-1}$ and $\alpha=(0.84 \pm 0.12)$ for the HArF formation kinetics and $k=(0.51 \pm 0.06) \mathrm{h}^{-1}$ and $\alpha=(0.67 \pm 0.07)$ for the $(\mathrm{ArHAr})^{+}$decay kinetics. This distinction between the fitting parameters suggests that the two processes are probably independent.

In some experiments with photolyzed $\mathrm{HF} / \mathrm{Ar}$ matrices, annealing above $20 \mathrm{~K}$ produced a band at $1377 \mathrm{~cm}^{-1}$. This band was assigned previously to the (FHF) ${ }^{-}$anion. ${ }^{26}$ The formation of negative ions along the decay of positive ions was somewhat surprising because one would rather expect the neutralization of the negative ions if the cations were globally mobile, as suggested in Ref. 9. In order to test this observation further, we performed experiments on $\mathrm{HBr} / \mathrm{Kr}$ solid mixtures, and the result is presented in Fig. 5. Irradiation at $193 \mathrm{~nm}$ decomposes $\mathrm{HBr}$ efficiently and a strong band of $(\mathrm{KrHKr})^{+}$is built up. A minor amount of $(\mathrm{BrHBr})^{-}$is also present after photolysis. ${ }^{27}$ After $135 \mathrm{~min}$ at $8 \mathrm{~K}$, about half of $(\mathrm{KrHKr})^{+}$decomposes, and the decomposition proportion is similar after several min at $34 \mathrm{~K}$. After $135 \mathrm{~min}$ at $8 \mathrm{~K}$, a small increase of $(\mathrm{BrHBr})^{-}$takes place, and the formation of the anions is strongly enhanced at $34 \mathrm{~K}$. As expected, our present annealing experiment did not show a formation of $\mathrm{HKrBr}$ species. The present data indicate similar decay rates for $(\mathrm{KrHKr})^{+}$generated in $\mathrm{HF} / \mathrm{Kr}$ and $\mathrm{HBr} / \mathrm{Kr}$ matrices, at least at $34 \mathrm{~K}$. The stability of $(\mathrm{KrHKr})^{+}$(in $\mathrm{HBr} / \mathrm{Kr}$ matrices) at $8 \mathrm{~K}$ is quite comparable with the stability of $(\mathrm{ArHAr})^{+}$in solid Ar. It was pointed earlier that the same qualitative conclusion is valid for elevated temperatures. Comparing the data at the lowest and elevated temperatures, we see that the annealing at $\sim 30 \mathrm{~K}$ accelerates the decay by about two orders of magnitude, and this is similar for $(\mathrm{ArHAr})^{+}$and $(\mathrm{KrHKr})^{+}$cations.

\section{DISCUSSION}

\section{A. Decay of $(\mathrm{NgHNg})^{+}$ions}

The tunneling and light-induced mechanisms for the global mobility of protons solvated in noble-gas solids were proposed by Beyer et al. ${ }^{8,9}$ These models could explain some previous experimental observations on the decay phenomenon of the cations, in particular, the isotope effect. Based on the present experimental data, the proposed models and additional possibilities can be reexamined. It seems that the effect is strongly dependent on sample preparation. For example, the short lifetime of $(\mathrm{ArHAr})^{+}(\sim 15 \mathrm{~min}$ as reported previously) ${ }^{6}$ is not reproduced in our experiments, which can be due to the different methods of sample preparation. The stability of $(\mathrm{ArHAr})^{+}$and $(\mathrm{KrHKr})^{+}$species is quite comparable in our experiments while the previous experiments showed a four-fold larger stability for $(\mathrm{KrHKr})^{+},{ }^{6}$ and the proton-tunneling model suggests the decay difference by several orders of magnitude. The decay of deuterons in Ar and $\mathrm{Kr}$ matrices is quite visible in our experiments, which does not fit accurately the proton-tunneling model predicting a slower decay of six to seven orders of magnitude for deuterons. A serious problem for models based on proton diffusion is introduced by the observed annealing-induced increase of the (YHY) $)^{-}$concentration. It looks natural to expect the bleaching of the negative centers upon global mobility of the positive charges, but the opposite effect has been documented (see Fig. 5). No reaction of the solvated protons with (YHY)- seems to occur, featuring, rather, the immobility of both species. The globar radiation is inefficient in promoting the proton decay so that the blackbody radiation is improbable to do this either.

An alternative explanation of the $(\mathrm{NgHNg})^{+}$decay is suggested here. The decomposition of the cations can be caused by their reactions with electrons stored in the matrix as a result of photolysis, and the transfer of the electrons to the positive center occurs via tunneling. The tunneling of electrons through very long distances is known in frozen matrices. ${ }^{28-30}$ Brus and Bondybey reported long-range $(1-2 \mathrm{~nm})$ electron tunneling from $\mathrm{C}_{2}^{-}$to a nearby cation in a Ne matrix. ${ }^{31}$

It is plausible to assume that the positive and negative charges generated in the matrix bulk upon photolysis are in equilibrium. The most probable electron trap is the electronegative fragment Y. It follows from the properties of solidstate photolysis that the negative and positive centers are formed in the vicinity of each other, and the distance is comparable with the lattice parameter $(\sim 0.5 \mathrm{~nm}) .{ }^{19}$ The energetics of this system allows the electron-tunneling process because the $(\mathrm{NgHNg})^{+}+e^{-}$neutralization reaction is strongly exothermic due to the large ionization energy of hydrogen $(13.5 \mathrm{eV})$. The total solvation energy of a proton with two $\mathrm{Ng}$ atoms is computationally $4.4,4.9$, and $5.3 \mathrm{eV}$ for $\mathrm{Ar}, \mathrm{Kr}$, and $\mathrm{Xe},{ }^{32}$ respectively, and the electron affinity of $\mathrm{Cl}$ is $3.6 \mathrm{eV}$ (the largest related value). The solvent reorganization energy, which results from the response of the medium to the change of the charge distribution between the initial and final states, and the electrostatic energy should also be considered; however, these contributions are not very large. In order to 
highlight the reality of this tunneling process, we estimate the probability of electron penetration through the $3-\mathrm{eV}$ rectangular barrier with a width of $1 \mathrm{~nm}$. The obtained value of $e^{-20}$ is sufficient to explain fast tunneling because the frequency of attempts is large. More important would be to model the dissipation of the free reaction energy by the $(\mathrm{NgHNg})^{+}$mode or by other mechanisms; however, this is a separate theoretical task.

The H/D isotope effect on the neutralization reaction should be commented. This isotope effect means that the electron tunnels faster to the $(\mathrm{NgHNg})^{+}$well compared with the tunneling to the $(\mathrm{NgDNg})^{+}$well (see Fig. 4). In general, this difference is probable if the role of the quantum modes of the cation is important for the energy dissipation. The deuteration decreases the frequency of vibrations, which influences the tunneling process. In this case, the normal isotope effect should be present if the free energy of reaction is large enough, and the effect can be in principle very strong (in modeling cases many orders of magnitude). ${ }^{33}$ Interestingly, the reversed isotope effect is also theoretically possible if the free energy of reaction is small. The observed H/D isotope effect suggests that overbarrier electron jumps are an improbable mechanism of the proton neutralization.

The electron-tunneling mechanism is capable of explaining the observed formation of the (YHY) ${ }^{-}$anions. They can be formed due to the tunneling of an electron from the $\mathrm{Y}^{-}$ center to the neutral $\mathrm{Y}-\mathrm{HY}$ center originated from the photolysis of HY dimers. First of all, this electron-transfer reaction is energetically possible because electron affinities of $\mathrm{Y}-\mathrm{HY}$ centers are larger than for Y. For instance, the electron affinity of $\mathrm{Cl}-\mathrm{HCl}$ is $4.6 \mathrm{eV}$, whereas that of $\mathrm{Cl}$ is $3.6 \mathrm{eV}^{34}$ As seen in the experiments, the (YHY) ${ }^{-}$formation is slower at low temperatures than the decay of the cations, which can be caused by larger distances involved or/and a small concentration of $\mathrm{Y}-\mathrm{HY}$ centers after photolysis. Indeed, during extensive photolysis, usually employed in our experiments, the $\mathrm{Y}-\mathrm{HY}$ centers are essentially destroyed. The $\left(\mathrm{YHY}^{-}\right.$anions are rather formed upon annealing (see Fig. 5). On one hand, this enhancement can be due to the thermal activation of electron transfer with a probable contribution from overbarrier jumps. On the other hand, it is possible that $\mathrm{H}$ atom mobility contributes to the (YHY)formation via increasing the $\mathrm{Y}-\mathrm{HY}$ concentration in the diffusion-controlled $\mathrm{H}+\mathrm{Y}_{2}$ reactions. It should be mentioned that the formation of the (YHY) ${ }^{-}$anions is inefficient in experiments with essentially monomeric samples. In contrast, the matrix in Fig. 5 has a relatively large $\mathrm{HBr} / \mathrm{Kr}$ matrix ratio of $1 / 500$ and it was deposited at $27 \mathrm{~K}$, which enhanced the dimer concentration.

The spatial separation of the $(\mathrm{NgHNg})^{+}$species from the negative fragments is important for their kinetic stability. The distribution of $\mathrm{H}$ atoms in the primary photolysis of $\mathrm{HY}$ is quite local; i.e., an essential part of the $\mathrm{H}$ atoms is trapped in the nearest interstitial sites from the parent cage, as discussed elsewhere. ${ }^{19-21,35}$ In particular, this local trapping of the $\mathrm{H}$ atoms is evidenced by experimentally found formation of the HNgY intermediates. ${ }^{11,18,19}$ The short-range stabilization of the hydrogen atom near the parent cage in the photolysis of $\mathrm{HBr}$ and $\mathrm{HCl}$ in solid $\mathrm{Ar}$ was reported. ${ }^{17}$ Some "hidden" processes take place upon photolysis, and they increase the distance of $\mathrm{H}$ atoms from the parent cage. First, in the secondary photolysis of the $\mathrm{HNgY}$ intermediates (if they exist) large excess energy is available making the flight distance larger. Second, following discussions in Ref. 20, the separation can be increased by light in cycles of ionization and light-induced neutralization. In this model, the mobilization of $\mathrm{H}$ atoms resulted from sudden light-induced neutralization of the $(\mathrm{NgHNg})^{+}$ion, giving kinetic energy for the light $\mathrm{H}$ particle. The direct neutralization of negative charges with concomitant attachment of the electron to the matrixisolated $\mathrm{S}_{2}^{+}$ions upon irradiation at $266 \mathrm{~nm}$ was suggested as the reason for the bleaching of the $\mathrm{S}_{2}^{+}$photoluminescence. ${ }^{36}$

\section{B. Low-temperature formation of HArF}

Now, we discuss the low-temperature formation of HArF. In principle, mobile electrons may assist this effect. Indeed, upon electron transfer from $\mathrm{F}^{-}$to (ArHAr) ${ }^{+}$the neutralization reaction can locally introduce some energy to a lattice and hence promote the $\mathrm{H}+\mathrm{Ar}+\mathrm{F}$ reaction, and this mechanism may be operating to some extent. However, the decay of the (ArHAr) ${ }^{+}$ions and the formation of HArF have different kinetics. Practically all (ArHAr) ${ }^{+}$ions are decomposed after $20 \mathrm{~h}$ at $8 \mathrm{~K}$ (see Fig. 4), whereas an essential part of HArF molecules are formed in additional annealing at $20 \mathrm{~K}$. Furthermore, the H/D isotope effect is quantitatively different for the (ArHAr) ${ }^{+}$decay and the HArF formation. Finally, the temperature dependence of these processes is different. In fact, HArF forms very quickly (during seconds) at $\sim 18 \mathrm{~K}$, whereas the $(\mathrm{ArHAr})^{+}$ions are still relatively stable even at higher temperatures (see Figs. 2 and 3). These facts suggest that the dominating mechanisms for the $(\mathrm{ArHAr})^{+}$decay and the HArF formation should be different.

We propose a possible mechanism for the lowtemperature HArF formation where the hydrogen atom tunnels to the Ar-F neutral center. The large H/D isotope effect is a good fingerprint of tunneling (see Fig. 4). This model finds support in literature. The tunneling mechanism was previously suggested to contribute to the local formation of HXeI after its IR decomposition. ${ }^{12}$ The excitation of the second $\mathrm{H}-\mathrm{Xe}$ stretching overtone produced short-rangeseparated $\mathrm{H}-\mathrm{Xe}-\mathrm{I}$ triads, which could restore $\mathrm{HXeI}$ via $\mathrm{H}$ atom tunneling. The short separation distance is needed for efficient $\mathrm{H}$ atom tunneling. Indeed, the short-range stabilization of hydrogen near the parent cage in the photolysis of $\mathrm{HBr}$ and $\mathrm{HCl}$ in solid $\mathrm{Ar}$ was experimentally shown. ${ }^{17}$ Our present results further support the locality of the HF photolysis in solid Ar.

Bihary et al. estimated the barrier of $\sim 0.3 \mathrm{eV}$ for the $\mathrm{H}+\mathrm{Ar}+\mathrm{F}$ reaction in an Ar matrix, the barrier thickness being $\sim 1.3 \AA{ }^{37}$ Even though the precise barrier shape is unknown and the available numbers are only estimates, we can conclude that the probability of penetration of this barrier is of a similar order to our earlier estimates for electron tunneling $\left(\sim e^{-20}-e^{-30}\right)$. This makes the tunneling process probable if the frequency of attempts is similar to the vibrational frequency of the interstitial $\mathrm{H}$ atom in a $\mathrm{Ng}$ lattice $\left(e^{30} s^{-1}\right.$ for 
$\mathrm{Xe}){ }^{15}$ The energy barrier for the $\mathrm{H}+\mathrm{Ar}+\mathrm{F}$ reaction estimated by Bihary et al. is very comparable with the parameters for isomerization of cis formic acid to trans formic acid controlled by $\mathrm{H}$ atom tunneling, ${ }^{38}$ which supports the possibility of the tunneling mechanism here. In contrast, the overbarrier thermal process is improbable at $8 \mathrm{~K}$ for these energy barriers. ${ }^{15,16}$

\section{CONCLUDING REMARKS}

We have studied experimentally the kinetic behavior of various neutral and charged species in UV-photolyzed noblegas matrices doped with hydrogen halides and discussed the involved formation and decomposition mechanisms.

First, the decay of $(\mathrm{NgHNg})^{+}$cations in $\mathrm{Ar}$ and $\mathrm{Kr}$ matrices is experimentally studied and analyzed. We suggest that this decay phenomenon can occur via a neutralization of the solvated proton by electrons. The mechanism of this neutralization reaction probably involves tunneling of an electron from an electronegative fragment to the $(\mathrm{NgHNg})^{+}$cation, and this mechanism is consistent with all the available experimental data including the H/D isotope effect. The proposed electron tunneling mechanism should be considered as an alternative to the previously suggested mechanisms based on tunneling-supported or light-induced diffusion of protons in noble-gas lattices. ${ }^{8,9}$

Secondly, we have found experimentally that the formation of HArF molecules occurs slowly but efficiently in photolyzed $\mathrm{HF} / \mathrm{Ar}$ matrices already at $8 \mathrm{~K}$. This remarkable phenomenon can be explained by the tunneling of a hydrogen atom, which is a probable mechanism based on the energetics calculated recently by Bihary et al. ${ }^{37}$ The tunneling mechanism is supported by the strong H/D isotope effect. The experimental data suggest that the HArF formation process is mainly independent of the decay of $(\mathrm{ArHAr})^{+}$cations.

There is definitely a room for further experimental and theoretical research of these processes.

\section{ACKNOWLEDGMENTS}

The Academy of Finland supported this work. A.L. is a member of the graduate school Laskemo (Ministry of Education, Finland). Discussions with Vladimir Feldman are gratefully acknowledged. Vladimir Bondybey is thanked for reading the manuscript and for useful comments.

\footnotetext{
${ }^{1}$ Chemistry and Physics of Matrix-Isolated Species, edited by L. Andrews and M. Moskovits (Elsevier, Amsterdam, 1989).

${ }^{2}$ V. A. Apkarian and N. Schwentner, Chem. Rev. (Washington, D.C.) 99, 1481 (1999)

${ }^{3}$ H. Kunttu, J. Seetula, M. Räsänen, and V. A. Apkarian, J. Chem. Phys. 96, 5630 (1992).
}

${ }^{4}$ D. E. Milligan and M. E. Jacox, J. Mol. Spectrosc. 46, 460 (1973).

${ }^{5}$ V. E. Bonbybey, G. C. Pimentel, and P. N. Noble, J. Chem. Phys. 55, 540 (1971).

${ }^{6}$ V. E. Bonbybey and G. C. Pimentel, J. Chem. Phys. 56, 3832 (1972).

${ }^{7}$ C. A. Wight, B. S. Ault, and L. Andrews, J. Chem. Phys. 65, 1244 (1976).

${ }^{8}$ M. Beyer, E. V. Savchenko, G. Niedner-Schattenburg, and V. E. Bondybey, Low Temp. Phys. 25, 814 (1999).

${ }^{9}$ M. Beyer, E. V. Savchenko, and V. E. Bondybey, Low Temp. Phys. 29, 1045 (2003)

${ }^{10}$ J. Lundell, L. Khriachtchev, M. Pettersson, and M. Räsänen, Low Temp. Phys. 26, 680 (2000).

${ }^{11}$ L. Khriachtchev, M. Pettersson, N. Runeberg, J. Lundell, and M. Räsänen, Nature (London) 406, 874 (2000).

${ }^{12}$ M. Pettersson, J. Nieminen, L. Khriachtchev, and M. Räsänen, J. Chem. Phys. 107, 8423 (1997).

${ }^{13}$ M. Pettersson, J. Lundell, L. Khriachtchev, and M. Räsänen, J. Chem. Phys. 109, 618 (1998).

${ }^{14}$ H. Tanskanen, L. Khriachtchev, J. Lundell, H. Kiljunen, and M. Räsänen, J. Am. Chem. Soc. 125, 16361 (2003).

${ }^{15}$ L. Khriachtchev, H. Tanskanen, M. Pettersson, M. Räsänen, V. Feldman, F. Sukhov, A. Orlov, and A. F. Shestakov, J. Chem. Phys. 116, 5708 (2002).

${ }^{16}$ L. Khriachtchev, M. Saarelainen, M. Pettersson, and M. Räsänen, J. Chem. Phys. 118, 6403 (2003).

${ }^{17}$ K. Vaskonen, J. Eloranta, T. Kiljunen, and H. Kunttu, J. Chem. Phys. 110, 2122 (1999).

${ }^{18}$ M. Pettersson, L. Khriachtchev, J. Lundell, S. Jolkkonen, and M. Räsänen, J. Phys. Chem. A 104, 3579 (2000).

${ }^{19}$ L. Khriachtchev, M. Pettersson, J. Lundell, and M. Räsänen, J. Chem. Phys. 114, 7727 (2001).

${ }^{20}$ M. Pettersson, L. Khriachtchev, R.-J. Roozeman, and M. Räsänen, Chem. Phys. Lett. 323, 506 (2000).

${ }^{21}$ L. Khriachtchev, M. Pettersson, and M. Räsänen, Chem. Phys. Lett. 288, 727 (1998).

${ }^{22}$ D. T. Anderson and J. S. Winn, Chem. Phys. 189, 171 (1994).

${ }^{23}$ L. Khriachtchev, M. Pettersson, A. Lignell, and M. Räsänen, J. Am. Chem. Soc. 123, 8610 (2001).

${ }^{24}$ L. Khriachtchev, A. Lignell, and M. Räsänen, J. Chem. Phys. 120, 3353 (2004).

${ }^{25}$ L. Khriachtchev, A. Lignell, J. Juselius, M. Räsänen, and E. Savchenko, J. Chem. Phys. 122, 014510 (2005).

${ }^{26}$ R. D. Hunt and L. Andrews, J. Chem. Phys. 87, 6819 (1987).

${ }^{27}$ M. Räsänen, J. Seetula, and H. Kunttu, J. Chem. Phys. 98, 3914 (1993).

${ }^{28}$ J. R. Miller, Science 189, 221 (1975).

${ }^{29}$ J. Kron and C. Stradovski, Int. J. Radiat. Phys. Chem. 7, 23 (1975).

${ }^{30}$ K. I. Zamaraev, R. F. Khairutdinov, and J. R. Miller, Chem. Phys. Lett. 57, 311 (1978).

${ }^{31}$ L. E. Brus and V. E. Bondybey, J. Chem. Phys. 63, 3123 (1975).

${ }^{32}$ M. Beyer, A. Lammers, E. V. Savchenko, G. Niedner-Schattenburg, and V. E. Bondybey, Phys. Chem. Chem. Phys. 1, 2213 (1999).

${ }^{33}$ J. Ulstrup and J. Jortner, J. Chem. Phys. 63, 4358 (1975).

${ }^{34}$ J. W. Larson and T. B. McMahon, Inorg. Chem. 23, 2029 (1984).

${ }^{35}$ L. Khriachtchev, M. Pettersson, S. Jolkkonen, and M. Räsänen, Chem. Phys. Lett. 316, 115 (2000).

${ }^{36}$ L. Khriachtchev, M. Pettersson, E. Isoniemi, J. Lundell, and M. Räsänen, Chem. Phys. Lett. 302, 324 (1999).

${ }^{37}$ Z. Bihary, G. M. Chaban, and R. B. Gerber, J. Chem. Phys. 119, 11278 (2003).

${ }^{38}$ M. Pettersson, E. M. S. Macoas, L. Khriachtchev, J. Lundell, R. Fausto, and M. Räsänen, J. Chem. Phys. 117, 9095 (2002). 